\title{
El estímulo de la duda
}

\author{
María Ángeles DurÁN \\ Instituto de Economía y Geografía \\ Consejo Superior de Investigaciones Científicas \\ dur@ieg.csic.es
}

Recibido: 25.03 .2008

Aceptado: 16.06 .2008

\section{EL ESTATUTO TEÓRICO DE LA DUDA}

En marzo de 2006 participé en un seminario del Instituto Alicantino de Cultura Jual Gil-Albert dedicado a la incertidumbre, que me obligó a reflexionar sobre la certeza y sus límites durante algunas semanas. Algo bastante de agradecer y un lujo casi desmedido para quien, como es mi caso, trabaja en el entorno de un Departamento de Economía de orientación empírica, y tiene como objetivo principal de análisis la Cuenta Satélite del Trabajo No Remunerado en la Contabilidad Nacional. Como casi todos los investigadores, mi trabajo ha de someterse periódicamente a las exigencias de un Informe de Actividades, en el que uno de los datos fundamentales es el número de artículos publicados y las citas conseguidas en revistas de reconocido prestigio internacional, hasta ahora prácticamente copadas por las de lengua inglesa. Tal condición convierte en poco rentable el esfuerzo de participar en seminarios de reflexión o de discusión interdisciplinaria, lo que tiene poco que ver con el interés sustantivo de los mismos.

Para hacer honor al grupo de investigación del CSIC del que formo parte («Tiempo y Sociedad»), en aquel seminario sobre la incertidumbre centré mis reflexiones en cuatro temas de hondo contenido temporal: el sueño (que interrumpe el tiempo consciente), la memoria (que se aleja del presente para trasladarse a tiempos pretéritos), la renovación (que amplifica el sentido del tiempo sin cambiar su dirección) y la muerte (que lo abandona definitivamente).

Fue un ejercicio teórico en el que traté de hallar correspondencias pictóricas a las ideas que iba desarrollando, y disfruté muchísimo, tanto en el seminario como durante la preparación del texto escrito. Como suele suceder cuando se encuentra una veta interesante, aquel ejercicio me supo a poco y quedé con ganas de seguir trabajándolo. Como los plazos editoriales son implacables, tuve que 
ponerle un cierre, dejando abiertas muchas cuestiones que desde entonces se me hacen patentes de vez en cuando, pero a las que me resulta difícil dedicarles el tiempo preciso por la presión de otras demandas más urgentes.

La invitación de Raquel Osborne a colaborar en este número de Empiria me recordó ese deseo desatendido, y creí que podría retomar las reflexiones donde las dejé un año antes, especialmente las referentes a la tensión entre investigación cuantitativa y cualitativa, que son una constante en mi actividad investigadora desde hace décadas. Vano intento, porque en medio se han cruzado otros proyectos y otras escrituras, que ni me permiten recordar con nitidez el punto en que estaba entonces, ni encuentro los materiales en que podría apoyarme para continuarlas. No obstante, y aunque buena parte de las ideas que en aquel momento flotaban entre las páginas a medio escribir se perdieran, al menos han sobrevivido dos que servirán de anclaje para este nuevo y demorado texto. La primera, que rescato sobre todo por tratarse de un trabajo para Empiria, la transcribo literalmente:

«Como antídoto a la presión para ofrecer certeza, yo recomendaría a los jóvenes que investigan sobre el tiempo con vocación empírica y deseos de exactitud que dedicasen algunas horas a familiarizarse con las obras de los artistas que se han ocupado del mismo tema. Aunque interrumpan momentáneamente su trabajo y pierdan rapidez en el avance, lo recuperarán luego con creces y con mayor profundidad».

Me llevaría demasiado espacio y tiempo la explicitación de las razones por las que sigue pareciéndome una buena propuesta $-\mathrm{y}$ no una pérdida de tiempo- - la invitación al arte a los jóvenes investigadores; tendré que conformarme con confesar que he seguido tratando de aplicarme a mí misma esta propuesta y que espero que antes o después produzca frutos concretos.

La segunda idea, la exponía allí —más o menos_ con estas palabras:

«La discoincidencia de resultados entre distintas fuentes genera incomodidad o suspicacia en los usuarios y en los medios de comunicación. Pero esos datos rebeldes, oscuros, son los que más atraen el interés del investigador, que atesora y colecciona sistemáticamente sus dudas para explorarlas en soledad, lejos de la presión mediática o la exigencia de resultados inmediatos» ${ }^{1}$.

\footnotetext{
${ }^{1}$ Me refería a las diferencias en la estimación del tiempo de trabajo no remunerado que aparecen de modo sistemático entre las encuestas realizadas por el INE y por el equipo de investigación «Tiempo y Sociedad» en el Consejo Superior de Investigaciones Científicas. Las estimaciones son muy similares, a pesar de utilizar diferentes metodologías y muestras de tamaño muy diverso, en lo referente al empelo o algunas actividades relativamente materiales como el cocinado. En cambio, las estimaciones se duplican en las encuestas del CSIC en las actividades de cuido, tanto en el número de participantes como en el tiempo dedicado. Las discoincidencias son asimismo considerables respecto a la asignación de valor al tiempo de trabajo no remunerado. Algunas publicaciones en las que he expuesto con mayor detalle este tema son «Integración del trabajo no remunerado en el análisis de los sectores de salud y bienestar social» y La contribución del trabajo no remunerado a la economía española.
} 
El estatuto de la duda es muy variable según la tradición intelectual en que se inserte. Mal vista en las organizaciones religiosas y políticas, es sin embargo cultivada metódicamente por corrientes filosóficas como el escepticismo y sus herederos cartesianos. En el campo de la ciencia moderna no tiene un lugar claro; choca contra el sentimiento de confianza en sus resultados, de rightness, que domina a numerosos investigadores, tanto en las ciencias naturales como en las sociales.

En el lenguaje común se manejan dos acepciones de duda que son entre sí profundamente diferentes, y muy relevantes para el proceso de investigación. Según la primera,

«duda es la suspensión o indeterminación del ánimo entre dos juicios o dos decisiones, o bien acerca de un hecho o una noticia» (Diccionario de la R.A.E.).

en tanto que, según la segunda, es:

«la cuestión que se propone para ventilarla o resolverla».

La suspensión o indeterminación del ánimo entre varios juicios alternativos, o ante varios datos, paraliza el proceso de investigación. Si continúa, será a costa de lateralizar el juicio o hecho que produce la duda, buscando vías indirectas que minimicen y permitan salvar el escollo aún a costa de no resolverlo. Los cierres en falso son frecuentes en la investigación por la escasez de recursos, las premuras de tiempo y la necesidad de presentar resultados; lo que no quiere decir que los hallazgos sean incorrectos, sino solamente que el proceso sirvió para detectar problemas a los que no se pudo prestar la suficiente atención o los recursos imprescindibles. Estos nudos no resueltos se plantean en cualquier etapa del proceso de investigación.

La segunda acepción de duda es casi opuesta a la primera, ya que en lugar de definirse por la «suspensión o indeterminación», conlleva justamente lo contrario, la propuesta de una acción para «ventilarla» o «resolverla». No deja de ser interesante que para salir de la duda el Drae no solamente recoja la posibilidad de «resolverla» («tomar una determinación fija y decisiva» $O$ «analizar, dividir física o mentalmente un compuesto en sus partes o elementos para reconocer cada uno de por sí»), sino, además, la de «ventilarla». Ventilar es agitar o exponer algo al efecto del aire, especialmente para renovar el aire enrarecido de una pieza cerrada. Figuradamente, se aplica también a hacer público un asunto privado.

En los tiempos de proceso de investigación, la duda definida por la segunda acepción acaece después, y secuencialmente, respecto a la primera. Rara vez las dudas pertenecen a un solo investigador, puesto que gran parte de las investigaciones se hacen en equipo, y las decisiones a asumir ante las dudas han de tomarse colectivamente, siguiendo no sólo estrategias individuales sino de grupo. El momento y modo de resolverlas tampoco lo deciden siempre 
los investigadores que tropiezan con ellas en su propio trabajo: tanto el modo como el momento pueden venirles dados desde fuera, desde la crítica de su investigación o desde los acuerdos que han ido sedimentando la cultura propia de su disciplina.

Además de la ocultación, el olvido o la imposición autoritaria y dogmática, que son formas de acallar las dudas sin resolverlas, la solución suele venir a través de una de estas tres vías:

a) La analítica, que consiste en descomponer el problema en sus partes constitutivas.

b) La social, que consiste en exponerlo ante otros auditorios para que lo analicen desde diferentes cualificaciones y perspectivas y sumen esfuerzos y capacidad de resolverla.

c) La psicológica, que es la decisión de romper el impasse o período de indeterminación, asignando a esta ruptura los recursos necesarios y, sobre todo, aceptando los riesgos que la toma de una u otra decisión conlleva.

En la investigación científica, la solución de dudas exige a menudo la repetición de los estudios realizados, pero la capacidad de descomponer el proceso en partes aisladas marca grandes diferencias entre distintos tipos de metodologías. Buena parte de la investigación en ciencias sociales es irrepetible por sus propias características de objeto o metodología; y otros tipos de investigación social, que no se corresponden con estas características, resultan en cualquier caso sumamente improbables de repetir por las limitaciones presupuestarias.

Para que la duda se convierta en un estímulo para la investigación tiene que ser manejable. Esto es, que se pueda reconocer, identificar claramente y se acompañe de la esperanza de poder superarla. De lo contrario, no actuará como estímulo como una barrera o fuerza disuasoria, prolongando indefinidamente esa «suspensión o indeterminación del ánimo» en el que las energías se agotan sin encontrarle cauce. El Diccionario de la R.A.E. define el estímulo como el «incitamiento para obrar o funcionar», y así actúan las dudas enriquecedoras. Pero tal invitación tiene sus límites y no debe llegar al nivel doloroso que acompañaba la acepción antigua y ya desusada de estímulo, como «vara con punta de hierro de los boyeros».

Algunas dudas son punzantes como aguijones, pero cuando me refiero a su capacidad estimulante estoy, sin duda, marcando objetivos menos drásticos.

Lo que sigue en las próximas páginas es una reflexión sobre aspectos de la investigación a los que generalmente se dedica poco espacio y relevancia, pero que a mí me resultan atractivos por sus implicaciones en la práctica cotidiana de la investigación.

a) La fragmentación del proceso científico.

b) La continuidad y autoría en la ciencia.

c) Los destinatarios y receptores de la investigación. 
d) La adaptación de los nombres (títulos) en el proceso de comunicación de resultados.

e) El balance del día de después.

\section{PLURAL Y SINGULAR: DE LA INVESTIGACIÓN A LAS INVESTIGACIONES}

En el sistema judicial, cuando existen dudas o disconformidades sobre un proceso, se recurre a una escalada de tribunales en la que los niveles de preeminencia están claramente establecidos. Sin embargo, el argumento de autoridad es difícil de aplicar en la investigación científica, aunque en la práctica se recurra también a la autoridad/prestigio personal de los investigadores y de las instituciones. No es raro que las entidades científicas reclamen para sí mismas, incorporándolo al propio nombre, el estatuto de autoridad intelectual. Lo que tanto sirve para explicitar intenciones como para solicitar reconocimiento externo.

Siempre me ha llamado la atención que, en España, el organismo estatal dedicado a la investigación se llame Consejo Superior de Investigaciones Científicas. Tanto consejo como superior son conceptos dignos de reflexión y más comprensibles por razones históricas que de otro tipo, pero lo que quiero subrayar ahora es la condición plural de las investigaciones y su adjetivación con el calificativo de científicas. Otras instituciones similares, como el CNRS francés (Centre Nationale de la Recherche Scientifique) se expresan en singular, ontologizando todas las actividades en una sola aunque asimismo acompañadas del cualificante de científicas. El CNR italiano (Consiglo Nazionale delle Ricerche) también adopta el plural. En los países de habla inglesa, y salvando las diferencias de estructura, no tiene sentido la cuestión, puesto que «research» vale tanto para el singular como para el plural.

¿Por qué se priorizó el plural en los momentos fundacionales del CSIC y por qué se ha mantenido sin cambios durante más de seis décadas? Ignoro si en el momento de la creación existió debate sobre la conveniencia de titularlo en plural o singular, pero al menos en los últimos veinte años no he tenido noticia de que esta cuestión mereciera discusiones, aunque sí las haya habido sobre los ya citados y más polémicos conceptos de superior y de consejo. El vocablo superior ha caído en cierto descrédito empujado por las tendencias democratizadoras y los problemas que genera su uso en relación con los pares. Actualmente dominan como indicadores de superioridad los más modernos de «avanzado», «de referencia» o «de excelencia». A menudo la condición de eminencia del CSIC desaparece en la traducción a otras lenguas. En inglés, la propia página institucional del CSIC se traduce como Spanish National Research Council. En cuanto a los medios de comunicación actuales, la mayoría transforman el nombre de Consejo en un simple «Centro», anulando la más pretenciosa condición consejera que se trasluce en la primera «c» de sus siglas. 
No todo son decisiones conscientes y lógicas en la adopción y mantenimiento de nombres institucionales, y no descarto que el mantenimiento del largo título del CSIC y todas las palabras que lo componen se deba más a las dificultades legales para modificarlo que a la entusiasta adhesión a su contenido, aceptado principalmente por inercia y costumbre y para evitar los engorrosos trámites de ajustarse a un nombre nuevo.

Incluso, aunque poca gente lo reconozca o siquiera sea consciente de ello, es posible que el nombre subsista tal como fue porque existe un latente problema de eufonía, o más bien de su contrario, y fonéticamente resulta duro que un título tan largo termine con una tonalidad sonora, como investigación, de vocal abierta y muy acentuada, seguida de otro vocablo igualmente retumbante en el oído, «científica», que es suave en la primera sílaba pero dura por la continuidad de las consonantes t y f, implosiva la primera y fricativa la segunda, acentuadas por la condición esdrújula de la palabra.

Resulta algo inquietante reconocer, o siquiera plantearse, que en cuestiones tan aparentemente sustantivas como el nombre de una institución científica puedan jugar un papel los elementos fonéticos o estéticos, pero más inquietante sería todavía que tal posibilidad se descartara por no correr el riesgo de considerarla.

Sea por unas razones o por otras, el nombre se ha mantenido estable desde los años cuarenta y los debates nominativos sólo se han producido — esos sí, con frecuencia y hasta virulencia - en niveles intermedios o menores, como la titulación de centros, institutos, grupos y departamentos. La pluralidad que el nombre del CSIC reconoce puede deberse a que los tipos de investigación que en su interior se realizan son variados, pero todos ellos han de caber bajo el paraguas común de la condición científica.

El término investigaciones, en plural, sugiere diversidad; diversidad temática y metodológica, lo que aplica bien a una institución en la que coexiste un variado arco temático que va de los centros de investigación biológica a los de filología; que utiliza principalmente técnicas experimentales, pero que no excluye los institutos de filosofía o de física teórica. Además de la diversidad temática y metodológica, el plural conlleva la idea de fraccionamiento, de interrupciones en un proceso, de pequeñas unidades de cuenta. No sólo hay diversos centros, institutos, departamentos y grupos de trabajo que investigan sobre diferentes líneas, sino que lo hacen con discontinuidades temporales y administrativas, creando y cerrando núcleos de micro-gestión en torno a proyectos sucesivos. Cada investigación es un producto concreto, generalmente acotado en tiempo, espacio, presupuesto y personas que participan en ella.

Frente a la referencia implícita a la diversidad, hace falta un contrapeso de unidad, que viene proporcionado por el marco común de la entidad bajo la cual se desarrollan las actividades de investigación, esto es, el Consejo como ente (ahora Agencia Estatal) dotado de personalidad jurídica propia. La unidad de la institución proporciona estabilidad frente a las tensiones territoriales y disciplinares. 


\section{LA AUTORÍA DE LA CIENCIA}

¿Quién hace la ciencia? La cuestión del sujeto de la acción siempre ha sido de interés para la teoría sociológica y lo es también para la sociología de la ciencia. Nominalismo o realismo son las opciones teóricas extremas, acompañadas de todas las variantes intermedias.

La dilucidación del sujeto de la ciencia, de quién lo hace, no es una cuestión meramente retórica, aunque rara vez se plantee abiertamente en estos términos. Forma parte de las creencias de los investigadores y afecta decisivamente a la forma y criterios de funcionamiento de las instituciones. Por ejemplo, se trasluce en el sistema de salarios y recompensas.

Aunque la misión de producir ciencia se encargue a universidades, centros académicos o institutos de investigación, los proyectos concretos de investigación han de explicitar el nombre del investigador principal, la persona individual que los dirige. El sistema de recompensa mediante sexenios (además de quinquenios, trienios y otros elementos vinculados con la antigüedad personal) es la mejor expresión presupuestaria de la idea de que la ciencia la realizan los investigadores individuales ${ }^{2}$. No obstante, otras recompensas se vinculan al cumplimiento de objetivos por los institutos, centros o departamentos, respondiendo a la interpretación institucionalista de la ciencia. En estos casos las partidas presupuestarias se reparten entre todo el personal, con independencia de su contribución individual a la producción científica del centro.

Los investigadores viven cotidianamente la tensión entre sentirse sujetos de la tarea que desempeñan y la de interpretarse como meras piezas en un engranaje externo que apenas les deja margen para sus proyectos individuales.

Entre los científicos naturales existe una interacción científica que en muchas áreas les permite funcionar como una verdadera comunidad científica. En las ciencias humanas y sociales, tanto la singularidad del objeto de estudio como la relevancia para la sociedad concreta en que el fenómeno se produce, es comparativamente mayor que en las ciencias naturales. El mimetismo, la subordinación lingüística y la dominación cultural como corolario de la política, son un riesgo muy real del que pocas veces se previenen las propias instituciones responsables de la investigación.

La sociología, como cualquier saber actual que desee reconocimiento, está muy influida por las ciencias experimentales. Sin embargo, en las ciencias sociales y en las humanidades es casi imposible realizar experimentos, si por experimento se entiende la reproducción de un hecho en condiciones de laboratorio y con suficiente aislamiento para determinar con precisión las relaciones causa-efecto entre las variables previamente seleccionadas.

${ }^{2}$ El rumor no tiene estatuto reconocido en la investigación científica, pero forma parte de la vida cotidiana de los investigadores. A veces es un avance de noticias, otras un globo-sonda, y otras, un simple globo-globo que se desinfla con el paso de los días. Al momento de escribir estas líneas corre insistentemente el rumor de que la queja inveterada por la escasez de este emolumento se ha visto atendida recientemente con una subida del $300 \%$. Si non e vero, e ben trovato. 
Por otra parte, la producción de información nueva mediante técnicas de observación extensiva diseñadas $a d-h o c$, que es probablemente lo más parecido a la investigación experimental de las ciencias naturales, es muy costosa y solo una reducida parte de profesionales consigue los fondos necesarios para aplicar regularmente estas técnicas a los temas de investigación que les interesan. Ni siquiera quienes trabajan en grandes centros de producción de datos tienen garantizado que podrán dedicarse continuadamente a los temas de su interés; las instituciones distribuyen sus recursos en función de variados intereses, entre ellos el mantenimiento de la continuidad de las fuentes y los compromisos con clientes políticos y comerciales, lo que deja un margen escaso a la libertad de elección temática y metodológica de sus propios profesionales. Por esta razón, entre muchos investigadores prima habitualmente la condición de técnicos (esto es, especialistas en el uso de los instrumentos y de la gestión) sobre la de analistas.

En España, en buena medida la investigación científica se importa, producida en el exterior y pagada en royalties o incorporada al precio de bienes y servicios. De la investigación que se produce dentro de las fronteras, una parte corresponde a la empresa privada, pero el grueso se realiza en entidades públicas. Las convocatorias I+D otorgan la máxima libertad temática y metodológica, pero son lentas en el plano administrativo y generalmente escasas en financiación y ofrecen poco incentivo económico a los investigadores. Las universidades no se dedican en exclusiva a la investigación, pero el gran número de profesores hace que su contribución al conjunto de lo producido sea muy elevada. Entre las instituciones públicas que tienen la investigación como objetivo principal o único, el CSIC es la más compleja y de mayor tamaño. El intento de fusionar todas las instituciones públicas de investigación en un centro único que se inició hace algunos años (por ejemplo, habría unificado el CIS con el CSIC) no prosperó y actualmente se mantiene la diversidad de adscripción administrativa y de funcionamiento de numerosos centros que de un modo u otro investigan desde las ciencias sociales.

Si la investigación fuese un proceso universal de acumulación de conocimientos en todos los campos, el destino de cada investigación concreta sería también universal, sin fronteras de tiempo o espacio. Pero la realidad es bastante más prosaica, y antes de incorporarse a una corriente mundial de conocimientos, los resultados de cada investigación han de atravesar infinidad de destinatarios parciales, que con frecuencia las absorben y metabolizan sin permitir el paso a otros destinos. De menor a mayor, el conocimiento que trata de hacerse universal tiene que ir superando sucesivas gradaciones de proximidad espacial y temporal, amplitud y profundidad. En el peor de los casos, los resultados de la investigación no llegan a nadie, no traspasan siquiera los límites del investigador que la llevó a cabo. Con más fortuna, pueden alcanzar superficialmente a algunos colegas inmediatos, o incluso ampliar su influencia hasta investigadores de campos afines o de entornos geográficos próximos.

La preocupación por el destino de la investigación impregna hoy el funcionamiento de las instituciones científicas. Los criterios de valoración dependen 
más de la valoración del impacto externo de cada producto - medido en publicaciones y citas- que de su calidad intrínseca, porque el primero se ha aceptado como el mejor indicador de la segunda. Lo que a veces es cierto, pero no siempre. Con frecuencia creciente, el marketing se antepone a la investigación sustantiva y el diseño se ajusta más a los objetivos de la última fase (la difusión) que a las fases precedentes.

\section{LOS DESTINATARIOS DE LA INVESTIGACIÓN Y LA SIMULTANEIDAD DE BÚSQUEDAS}

La organización de las ciencias sociales está muy influida por las ciencias naturales, y esta influencia es evidente en las convocatorias de los programas nacionales de investigación, que en cierto modo marcan la pauta para todas las restantes convocatorias de proyectos científicos:
a) título,
b) estado de la cuestión,
c) hipótesis,
d) definición de variables,
e) operativización,
f) propuesta de nuevas indagaciones y
g) transferencia o difusión de resultados.
h) Y, si fuera posible, patentes derivadas.

Esta es, resumidamente, la estructura de investigación que se espera sigan los proyectos y también la que se espera que reproduzcan sus productos secundarios, como artículos o libros.

Por comparación con la investigación de orientación académica o científica, los estudios realizados para clientes — sean privados o públicos- han de desarrollarse generalmente en plazos más cortos y los aspectos metodológicos son menos centrales. No quiere decirse con esto que no importen, sino que el cliente no va a discutirlos en detalle porque confía globalmente en la calidad del investigador a quien encarga el trabajo. Otro tanto sucede con algunas partes del proceso de investigación (la introducción sobre antecedentes, estado de la cuestión, bibliografía y referencias a posibles caminos por los que continuar la investigación en el futuro) que son consideradas casi imprescindibles en la investigación realizada bajo las convocatorias I+D, pero no lo son tanto en los estudios para clientes ajenos al mundo académico.

Los manuales de seguimiento de los proyectos de investigación que aspiran a la excelencia son también bastante lineales; y asimismo la estructura que habitualmente adoptan las memorias finales de rendición de cuentas. La práctica, no obstante, es menos mecánica, menos rígida y menos focalizada. Los investigadores se atienen a ese esquema sólo en grandes líneas, y más en las visiones a 
posteriori, justificativas, que en el proceso real de investigación. Raras son las investigaciones tan focalizadas que no dejen paso a algunas escapadas laterales al margen de la línea principal. Lo que podría interpretarse como una pérdida de recursos a consecuencia de un diseño poco claro, con su consiguiente valoración negativa, tiene muchos aspectos positivos, siendo el principal la posibilidad que ofrece de mirar desde cierto distanciamiento el propio proyecto y de ensayar otras técnicas, otras perspectivas.

En teoría, los períodos de interregno o pausa entre un proyecto y el siguiente, son los más adecuados para que el investigador explore temas y técnicas nuevas; pero en la práctica las pausas tiende a interpretarse como períodos carenciales, y los investigadores profesionales sufren agudamente la presión para embarcarse en nuevos proyectos. En cambio, los períodos con cobertura administrativa y económica garantizada ofrecen cierta estabilidad y es al amparo de esa tranquilidad, y con el acicate del propio proceso en marcha al que puede retornarse como a puerto seguro cuando las expectativas de la búsqueda colateral se agoten, como se estimula el deseo de apartarse moderadamente de la línea principal y explorar caminos nuevos.

El tema de la comunicación, al que antes me refería, no se plantea solamente al final de proceso, cuando ya hay resultados. Desde el principio aparece en los formularios de las convocatorias, por ejemplo en las de los proyectos I+D+I, aunque no la llaman por ese nombre. En los apartados correspondientes, por una parte se requiere información sobre los beneficiarios del proyecto; y por otra, sobre los medios que van a utilizarse para la difusión de resultados. Los formularios preguntan mucho porque se trata de financiar el proyecto o no, y hay dinero y poder por medio; pero todos, los que rellenan formularios y los que luego los leen, saben que hay respuestas obligadas y respuestas que nunca se reconocerán; y aún menos, por escrito.

Todo lector sabe que un artículo ( - o un capítulo de libro, que tanto da a estos efectos-) es un texto destinado a la comunicación. El autor lo escribe pensando en un público o audiencia concreta, aunque no pueda imaginarla con entera precisión; una audiencia a la que querría llegar con tino, pero tanto más difícil de satisfacer cuando más heterogénea sea, o más dispersos y encontrados sean sus intereses. En las revistas científicas, a veces también se pregunta por la comunicación o destino final del artículo que envía el autor, pero generalmente no se insiste en ello porque aspirantes y editores consideran la publicación como un fin en sí mismo, que agota el proceso comunicativo.

Existe el sobreentendido, que rara vez se pone en duda, de que el destinatario de la investigación — de cualquier investigación, sociológica incluida- es la comunidad científica internacional, que es tanto como decir el conocimiento universal. Sin embargo, es un supuesto que difícilmente se cumple, y no sólo por la dificultad de que un conocimiento concreto pase a incorporarse a un conocimiento universal (parcelación de los campos del saber, áreas lingüísticas, barreras a la difusión, etc.) sino porque no es esa la voluntad de quienes llevan a cabo las investigaciones. 
En muchos casos, el investigador estudia o investiga principalmente para sí mismo. Para responder a sus propias dudas. Y en ese caso, que comparta o no el resultado de sus indagaciones es secundario, un producto derivado al que las circunstancias pueden forzar o disuadir. En otros, y muy numerosos, tipos de actividad científica, el investigador trabaja para la entidad que financia sus investigaciones, cuyo interés es, precisamente, el acceso exclusivo a los resultados de la investigación. La incorporación a un nivel más amplio de acceso por parte de la comunidad científica depende de que esta difusión se considere o no conveniente para la entidad patrocinadora. $\mathrm{O}$ de que el investigador tenga interés en publicitar su relación con la institución, trasladando a otros circuitos la asociación de nombres. En esta situación se encuentran la mayoría de los investigadores que trabajan para entidades privadas, y también gran parte de los que trabajan para entidades públicas o sin ánimo de lucro. En España, donde los fondos para la investigación que se realiza en las Universidades o en el CSIC provienen en buena medida de otras entidades públicas, en los convenios o contratos de investigación es habitual la cláusula que reserva la propiedad de los resultados a las entidades financiadoras, que suele ir acompañada del derecho a la exclusiva en el manejo de los datos o al establecimiento de períodos de embargo (por ejemplo, de seis meses) sobre los mismos.

En los casos en que el investigador no tiene límites externos a la difusión, existen otros límites derivados de sus propios intereses, que afectan a todo o, más frecuentemente, a parte de lo investigado. La no-difusión afecta sobre todo a estos tipos de resultados:

a) Aquellos cuya metodología presentó dificultades.

b) Los que llegan a conclusiones poco definitivas.

c) Los que podrían entrar en competencia con otras investigaciones del mismo investigador o equipo de investigadores.

d) Aquellos que se desea «preservar» de una difusión mediocre para lanzarlos en contextos más brillantes o restringidos.

e) A los que no se quiere dar a conocer para no dar «pistas» a la competencia en momentos todavía embrionarios.

f) A los que forman o pueden formar parte de tesis doctorales, concursos o premios (en este tema, algunas universidades han introducido espectaculares cambios de criterio, primando los avances ya publicados) en centros que exigen la condición inédita de lo presentado.

\section{LOS TÍTULOS NÓMADAS}

Lo que quiero destacar en este epígrafe es la continuada elaboración del título y sus sucesivas transformaciones a lo largo del proceso de investigación; de ahí la denominación de títulos nómadas.

Los nombres de las cosas son importantes, sirven para identificarlas, para enviar a los otros un mensaje sobre lo que son. Sin embargo, los títulos de los pro- 
yectos de investigación suelen sufrir transformaciones a lo largo del tiempo, según el interlocutor o público al que van dedicados. El título condensa la idea principal (a veces, jugando con una metáfora) y en el subtítulo se ofrece una pista sobre el contenido y los subtemas o variables principales que se han analizado. No hay que minusvalorar la importancia de los títulos atractivos, y menos aún en materia como las ciencias sociales, donde frecuentemente existe una implícita, o incluso explícita, vocación de contribuir al cambio social por la vía del análisis. Los títulos reflejan estrategias de comunicación, y vale la pena subrayar su importancia porque se conectan con el pantanoso terreno del «impacto», que tanto preocupa hoy en las evaluaciones de calidad o excelencia.

La mayoría de los títulos con los que arrancan los proyectos de investigación $\mathrm{I}+\mathrm{D}+\mathrm{I}$ en ciencias sociales son largos, descriptivos y aburridos. Los autores enuncian el tema y las variables principales, acotando generalmente el ámbito de estudio por sus límites de espacio y tiempo. Como el título de los proyectos es largo y difícil de recordar, enseguida le nacen dos nuevos subtítulos. Uno de ellos no es obligatorio por ahora, pero empieza a ser tan frecuente que pronto lo será; consiste en un acrónimo formado con las iniciales de cada una de las palabras que componen el primer título originario. La realidad es menos lineal de lo que esta regla tan simple de ayuntamiento de iniciales pudiera sugerir. La gramática y la fonética imponen también sus reglas aunque no se citen, y los autores dedican su buen esfuerzo a buscar acrónimos pronunciables, que suenen bien y se asocien con las ideas adecuadas. Sobre todo, a cerciorarse de que eliminan los malos acrónimos que podrían perjudicar el proyecto; de modo que frecuentemente el acrónimo acaba determinando el título original, en un proceso interactivo en el que se añaden o quitan palabras, se buscan sinónimos o se modifica el orden de aparición de cada idea.

El título que sí resulta obligatorio y sustituye al que le dieron sus autores es la clave. La clave consiste en un conjunto número-alfabético que los expertos en gestión asignan al proyecto. Resulta incomprensible para casi todo el mundo, lo que paradójicamente le otorga inmediatamente un valor mistérico. Encierra las referencias al campo por el que el proyecto será administrado, la posición ordinal de la solicitud, año de comienzo o finalización, etc.

Como los proyectos de investigación I+D+I están integrados en una compleja estructura administrativa, una vez que se inician, los títulos quedan cristalizados y no se pueden modificar. Así se mantienen en las memorias intermedias y finales. Además, las buenas prácticas de lealtad hacia la institución patrocinadora requieren que el patronazgo siga siendo recordado años después, cada vez que sale a la luz un producto derivado de los proyectos, lo que generalmente se hace adjuntando a pie de página la clave numérica. El lector de tales publicaciones posteriores no suele identificar la referencia, ni hacerse una idea clara sobre lo que trataba el proyecto.

En los proyectos que no forman parte de grandes programas de investigación, los títulos tienen más variabilidad, tanto en el modo de componerse en primera instancia como en la posibilidad de modificarse a lo largo del proceso. El 
ejemplo más claro son las tesis doctorales, que suelen nacer bajo un título provisional muy amplio, tentativo, y van luego poco a poco modificándose y restringiéndose hasta hacerse firmes, y generalmente más modestas y precisas, en el nuevo título definitivo que se le asigna poco antes de su lectura. Definitivo porque se registra administrativamente en la Universidad y se asocia ya al futuro $\mathrm{cu}$ rrículum vitae de su autor o autora; pero provisional en cuanto identificador de la obra, porque tan pronto la tesis reciba el apto o cum laude correspondiente, empezará una nueva etapa, la de la búsqueda de editores. Lo más frecuente es que el viejo título se deseche, porque sirvió para aquellos a quienes iba destinado mientras el texto fue solo una aspiración de tesis. Ya no servirá para los nuevos lectores con quienes ahora busca conexión su autor, que suelen preferir títulos más cortos, menos especializados y más atractivos, aunque describan con menos exactitud su contenido.

Como ejemplo del nomadismo de los títulos voy a exponer una experiencia reciente que conozco bien, la del último informe que he redactado. El título que llevaba en mente al inicio del proyecto era «El techo de cristal», y la búsqueda de ese techo o barrera semi-invisible en las trayectorias de estudio y empleo de las mujeres era lo que impulsaba mi esfuerzo. Sintonizaba bien con otras actividades simultáneas de la entidad que financiaba el estudio, el Círculo Olay, mucho más conocido por sus becas de retorno al estudio para mujeres que tuvieron que interrumpirlo que por las aportaciones a la investigación sociológica. Pensé que era un título útil y sinérgico, y las huellas académicas se habrían podido apuntar en el subtítulo «Mujer, educación y empleo». Sin embargo, a las pocas semanas de trabajo me di cuenta de la dificultad de trasponer a otros ámbitos de actividad, otras épocas y otros niveles sociales una idea surgida para describir las dificultades de promoción de las mujeres ejecutivas. Para entonces ya había realizado muchas incursiones buscando materiales en las prometedoras Encuesta de Condiciones de Vida (2005), la Encuesta de Empleo del Tiempo (2002-2003) y las series trimestrales de la Encuesta de Población Activa, todas ellas del INE, y me parecía más interesante tratar de rastrear los cambios en el conjunto de la población que en algunos grupos de élite, como podrían ser las mujeres con educación universitaria.

Por supuesto, un cambio de título no se produce de repente, es también un proceso que requiere un tiempo de desarrollo. En este caso, acabó de cuajar tras la experiencia de búsqueda de nuevas fuentes a través de Internet. La gente de mi edad aprendió a investigar en bibliotecas y se encuentra muy apegada a la documentación sostenida sobre soporte papel: libros, revistas tradicionales que se hojean y tocan con las manos, literatura gris difícil de clasificar que encierra a veces pequeños tesoros. Todo esto empezó a tambalearse hace unos años con la difusión de Internet y hoy es casi una reliquia del pasado. Como prueba, las convocatorias de los planes nacionales de I+D+I, en que las claves de referencia para presentar solicitudes, sólo se consiguen después de una hábil cuadratura de formularios y curriculum a través de la pantalla.

Aunque en la investigación en ciencias sociales todavía juegue un papel la biblioteca física, la biblioteca virtual está desplazándola a toda velocidad: fren- 
te al lugar, el espacio móvil de las ondas. Aquellas fuentes periódicas de información que eran las estadísticas del INE, clasificadas en los estantes de las librerías por formatos identificables a simple vista, han desaparecido para transformarse, en el mejor de los casos, en cd's brillantes que apenas ocupan espacio. La información llega ahora con más rapidez y es más accesible, los datos pueden trabajarse con facilidad, pero siempre a condición de que se llegue a ellos a través de Internet y se manipulan e impriman con el software adecuado. Si en los proyectos de larga duración ya es muy necesario el apoyo de los recursos accesibles vía Internet, en la investigación de formato temporal breve (hasta seis meses) se convierte en casi imprescindible, haciendo cierto el dicho de que «lo que no esté en Internet, no existe». Internet no es una facilidad añadida, sino un marco. Ante la limitación del recurso-tiempo, el investigador no puede desplazarse a buscar información fuera de su entorno espacial inmediato y prima absolutamente la información que llega hasta su mesa de trabajo moviendo solamente el puntero del ratón. Aunque en muchas ocasiones, no sea consciente del proceso de selección al que le fuerza esta criba.

Por todo lo expuesto, fue vía Internet como empecé a buscar información añadida a la que ya tenía ubicada sobre las barreras a la continuación de los estudios y a la promoción laboral. No la única vía, claro, pero sí la más importante. Lamentablemente, lo que la pantalla me facilitó sobre el techo de cristal era poca cosa.

En la búsqueda de alternativas al techo de cristal para facilitar los itinerarios del Google, desplegué un abanico de conceptos próximos o afines. Ahí emergió con gran cantidad de referencias el concepto de fracaso escolar. La idea de fracaso encaja más fácilmente con las interpretaciones individualistas y por tanto psicológicas, porque requiere un sujeto y un discurso claramente identificable. Esta idea había logrado un espacio importante en la red, pero se vinculaba sobre todo con problemas psicológicos individuales y con servicios sociales o terapias de ámbito local. No era eso lo que estaba buscando, pero en cualquier caso me obligó a unos cuantos debates internos (o sea, conmigo misma) sobre el nivel de atribución de causas y de interpretación de resultados educativos; la opción entre el propio individuo o las estructuras sociales. Y, asimismo, sobre las posibilidades de intervención y la evaluación de políticas públicas, lo que es casi el principio de una reflexión sobre el papel que juegan hoy la sociología y los sociólogos en el panorama profesional español, por comparación con el que jugaron en la época de la transición democrática.

Sobre el éxito escolar y laboral, la red aportaba menos información que sobre el fracaso; supongo que - al igual que las patologías en medicina - porque duele y hay que ponerle remedio. Además, last but not least, porque en la reparación del fracaso es donde encuentran hueco profesional más fácil los propios reparadores intervencionistas que propagan la noticia.

Digamos, para resumir, que la información que me llegaba vía Internet se alejaba en exceso del tema que me interesaba, y que la información proveniente de las encuestas me parecía más abundante y consistente. 
Hay quien piensa que la investigación es aburrida y que los momentos en que una vía se revela inútil son frustrantes. Algo de razón llevan en esto último, pero debieran saber que el portazo de las fuentes suele ser solamente el preámbulo de uno de los momentos más creativos y divertidos de la investigación, la búsqueda de alternativas. De algún lugar del fondo de la personalidad del investigador (¿del alma, del carácter, del hábito, dirían otros?) se despiertan unas energías dormidas, impetuosas, que no aceptan el no por respuesta. Y el otrora tranquilo estudioso se transforma por unos días en un sujeto racionalmente aventurero, un rastreador de huellas y caminos aún no explorados que se parece muy porco al burócrata con el que en otros momentos se identifica.

En el proyecto al que me refiero, hubiese podido acotar más el período histórico, centrarme en la educación o sólo en las mujeres, o usar un único instrumento de observación, con lo que habría conseguido una investigación más lineal y compacta. Pero preferí abrirla por varios flancos, hacerla compleja y, consecuentemente, menos legible.

¿Con qué sensómetro o evaluómetro podría medir el interés y el placer que experimenté en la búsqueda simultánea a través de diversas fuentes? No sé si los lectores están familiarizados con esa sensación de pobreza y riqueza que a menudo asalta furiosamente a los investigadores -0 les acompaña en un nivel menos agudo durante períodos largos- y nada tiene que ver con la donación financiera ni el pago por nuestros servicios. Es la riqueza de estimulación, de apertura, de posibilidades de conocer. En ese sentido tengo que decir que el proyecto que vengo comentando, tan libre, fue para mí muy enriquecedor. Aunque, tal vez, no convenga reconocerlo en voz alta para que no caigan los promotores en la tentación de pedirme que devuelva los honorarios porque me consideren sobradamente pagada en atisbos y sueños.

Como el tiempo es un recurso muy escaso y los plazos vuelan, tuve que optar. Me decidí por la línea más empírica, contando con las encuestas del INE como trasfondo. Diseñé una nueva encuesta de ámbito nacional que titulé «Encuesta sobre Educación y Empleo, 2007», (2400 entrevistas, 1200 a hombres y 1.200 a mujeres), que se complementaba con una serie de veinte entrevistas de carácter no representativo a mujeres que hubieran interrumpido sus estudios, y a expertas o responsable en institutos de igualdad.

A medida que avanzaba el proceso y llegaban a mis manos los primeros resultados de la encuesta y las primeras entrevistas personalizadas, se hacía más difícil el mantenimiento del título inicial. La edad y la clase social eran variables tan decisivas en la interrupción de los estudios de la mayoría de los entrevistados que eclipsaban el efecto del «techo de cristal». No es que no lo hubiera, sino que las encuestas generales no son el mejor instrumento para detectarlo, y en cambio sí sirven para detectar otros efectos que actúan con mucha fuerza en otras fases previas de la vida de los entrevistados.

Me costó mucho abandonar la idea del techo de cristal, y más aún reconocer abiertamente algunas de las razones de mi propia resistencia: ¿cómo explicar que la sonoridad de la palabra cristal, su inmediata asociación con la idea de fragili- 
dad, con el peligro de los vidrios rotos cayendo sobre la cara de quien osa golpear el techo, me daba energías para sumergirme en el torbellino de cifras que escupían las encuestas?

En la elección del título definitivo pesó mucho el de la encuesta realizada adhoc para él. Gran parte del presupuesto del proyecto fue a parar ahí, y reproducirlo en el informe final era una manera de realzarla. Aunque también podría interpretarse que la decisión se fue prefijando al titular la encuesta, como un ensayo para calibrar su propia eficacia.

Con el análisis de la encuesta propia y de las restantes fuentes de observación extensiva ya casi terminado, todavía seguía barajando varias versiones para el título. Hubiera sido correcto titularlo simplemente «Mujer, educación y empleo». $\mathrm{O}$ «Mujer, educación y el futuro de la promoción en el empleo», lo que habría puesto punto final a la disquisición y me hubiese ahorrado muchas horas de darle vueltas. Pero lo cierto es que no podía cerrar el estudio con un título tan impersonal y tan plano, y menos todavía en una ocasión en que las propias características del informe (para una entidad privada, sin compromiso de publicación excepto en un pequeño resumen ejecutivo para los medios de comunicación asistentes al acto en que se presentaba) me otorgaba una gran libertad de decisión. En aquel momento, tras muchas semanas de trabajo intenso y poco tiempo para dormir, el cansancio empezaba a hacer mella. Para mantener alto el nivel de energía necesitaba sustituir el título del estudio por otro que me motivase suficientemente; y lo encontré. Sin que aún se reflejase en los borradores y sólo para mí misma, comencé a titularlo «El deseo de saber», con ligeras variantes léxicas en la idea del deseo, que a veces subía de diapasón para denominarse pasión de saber o se reducía a otra versión menos volitiva y más en consonancia con lo políticamente correcto, como «las oportunidades de acceso al saber».

Siempre fui consciente de que «saber» es un término mucho más ambicioso que la simple escala de grados del sistema educativo, que es la que en realidad medían las encuestas. Aunque la correspondencia no es ni mucho menos perfecta, acepté de buen grado la sustitución de una cosa por otra, y no traté de incorporar definiciones del saber, y menos aún, de operativizarlo a través de otros indicadores educativos.

Como justificación de esta elección —en el supuesto de que alguien me pidiese explicaciones - podría alegar que eso es lo que en el fondo destilaban las encuestas, un deseo de saber conservado durante lustros, mitigado en muchos casos por el dolor de no haber podido hacerlo realidad.

A toro pasado y a sabiendas de que nadie me pidió explicaciones y de que dispuse de márgenes suficiente de libertad para nominarlo como quisiera, me pregunto ahora si había, además, otras razones para darle ese nombre. La respuesta es afirmativa. Creo que con «el deseo de saber» se cumplieron dos objetivos:

a) La conversión de un tema negativo, como la barrera del techo cristal, en un tema positivo.

b) La proyección personal en el propio título. 
Con la referencia al deseo de saber reducía la importancia del fracaso y el abandono, destacando los aspectos más favorables del tema estudiado. Y al mismo tiempo, — si se me permite la comparación, como los pintores que se pintaban a sí mismos en un ángulo del cuadro- utilizaba el título para autoproyectarme, para convertirlo en espejo personal y colectivo. Porque, ¿qué otro rasgo caracteriza al/los investigadores y le hace sentirse identificado con los que se vieron deprivados de la oportunidad de hacerlo, sino su permanente deseo de estudiar y de saber?

Comencé este epígrafe refiriéndome al carácter nómada de los títulos y sus sucesivas transformaciones para ajustarse al contexto destinatario. Raros son los estudios largos que se publican completos de una sola vez, y es muy frecuente que en sucesivas publicaciones vayan apareciendo fragmentos relativamente independientes. Es lo que ha sucedido ya en el estudio referido, del que se encuentra en prensa un artículo que, a partir de algunos de los datos más destacados; continúa profundizando en su análisis. Formará parte del libro-homenaje a Miguel Beltrán que editará el Centro de Investigaciones Sociológicas, y en ese artículo, - como en cualquier otro-, tuve que realizar un proceso de selección hasta decidir el título que me pareció más adecuado. Por tratarse del homenaje a un colega compañero y amigo, el destinatario no fue sólo la incorpórea comunidad científica, sino una persona concreta, el autor en cuyo honor los demás hemos escrito nuestras colaboraciones. La mía va a llamarse «El éxito, el fracaso y la esperanza», pero me limitaré a apuntar este nuevo nomadismo o ramificación respecto al proyecto inicial. Si alguien quiere conocer las razones de la elección de esas palabras y no de otras, le remito a que las busque directamente en la obra.

\section{EL BALANCE DEL DÍA DE DESPUÉS}

Supongo que no soy muy original al reconocer que suelo hacer un balance el día de después. Después de entregar un proyecto, un artículo, de terminar un curso, de acabar una investigación. Cuando cualquiera de estos productos del trabajo intelectual pasan por su último trámite administrativo o de difusión ante los medios, llega el momento del cara a cara sin testigo, lo que los escritores literarios llamarían probablemente la soledad del autor ante su obra.

Igual que muchos de mis colegas, hago un balance racional, desapasionado, una rápida valoración de resultados; por un lado los intelectuales, por otro todos los demás. El debe, el haber, y el equilibrio no siempre conseguido. Lo que salió bien y lo que salió mal. Lo que ha dejado puertas abiertas para más adelante y lo que se ha cerrado. Y el balance, tan importante, de las relaciones humanas: no sólo en la investigación y su entorno, sino en la familia y los amigos. ¿Realmente, valió la pena el esfuerzo?

El ejercicio de contabilidad intelecto-afectiva-económico-social sigue unos patrones lógicos, prolonga a otro ámbito la habitual actividad analítica del in- 
vestigador. Sin embargo, en el día de después tiene cabida otro tipo de actividad intelectual más desordenada, muy contagiada de afectividad. El investigador/a dialoga consigo mismo con una libertad y laxitud de reglas que no se ha autopermitido durante el proceso de investigación. Con la guardia bajada, abre y cierra soliloquios, parlamentos íntimos. Los soliloquios no se someten a reglas y el pensamiento viene y va desordenadamente, acompañado de ondas de desigual intensidad afectiva. Sería imposible transcribir con fidelidad estos procesos abiertos en que los sentimientos se funden con las palabras no dichas. La lógica habitual del discurso científico, con la concatenación de sujeto/verbo/predicado, no es un objetivo a perseguir ni está presente. Lo que no quiere decir que sea un intervalo antilógico, sino que se escapa hacia otro tipo de operaciones mentales. Con todo, es un momento muy perceptivo, muy creativo, en que muchos conceptos que por exigencias del guión (léase cuestionarios, operativización, etc.) se han mantenido como petrificados durante toda la investigación, se sueltan de sus encuadres para girar hacia otras perspectivas y para examinar críticamente -que no formalmente-, sus orillas y para explorar puentes y aperturas hacia otros conceptos. También es un momento de cambio de centralidades, de proporciones, de focos.

La última etapa de producción suele ser cansada, y en el día de después se mezclan los sentimientos de liberación y de agotamiento. No es raro que en las fechas próximas al límite de plazos, los temidos deadlines, el proyecto parezca un monstruo sin piedad que devora al investigador, robándole vida personal, ocio, sueño. Ni que muchos investigadores afronten un estado de ánimo melancólico y juren no volver a comprometerse nunca más en tales empresas. Hasta la próxima.

Algo nuevo se aprende en cada investigación, y algo que no se sabía que se desconocía, se hace patente. No se termina nunca de saber, sólo se van sustituyendo unas dudas por otras; supongo que en eso consiste, precisamente la grandeza y la miseria de la ciencia.

\section{RESUMEN}

Este artículo parte de la aplicación del concepto de duda aplicado al proceso de investigación científica. Se ofrece una reflexión sobre aspectos de la investigación generalmente no tratados, pero que resultan atractivos por sus implicaciones en la práctica cotidiana de la investigación. De este modo, se trata la fragmentación del proceso científico, la continuidad y autoría de la ciencia, los destinatarios y receptores de la investigación, la adaptación de los títulos en el proceso de comunicación de resultados y el balance del día después.

\section{PALABRAS CLAVE}

Duda, proceso de investigación, ciencia. 


\begin{abstract}
This article starts applying the concept of doubt to the scientific research process. It is presented an analysis on some aspects of research that, in spite of being barely tackled, are attractive because of their implication in everyday research practice. Therefore, it deals with the fragmentation of research process, the continuity and authorship of science, the recipients and the addressees of research, the adaptation of titles in the process of research results presentation and the balance of the day later.
\end{abstract}

\title{
KEY WORDS
}

Doubt, research process, science. 